\title{
Vaccine hesitancy among Sudanese parents and its association with the uptake of measles vaccine
}

\author{
Majdi M. Sabahelzain ${ }^{1,2 *}$, Mohamed Moukhyer ${ }^{3,4}$, Bart van den Borne ${ }^{2}$, Hans Bosma ${ }^{5}$ \\ 1 Department of Public Health, School of Health Sciences, Ahfad University for Women, Sudan; majdisa- \\ bahelzain@gmail.com \\ 2 Department of Health Promotion, Care and Public Health Research Institute (CAPHRI), Maastricht Univer- \\ sity, the Netherlands; b.vdborne@maastrichtuniversity.nl \\ 3 Education Development and Quality Unit, College of Applied Medical Sciences, Jazan University, Kingdom \\ of Saudi Arabia; moukhyer@hotmail.com \\ 4 Faculty of Medicine, University of Limerick, Ireland \\ 5 Department of Social Medicine, Care and Public Health Research Institute (CAPHRI), Maastricht University, \\ the Netherlands; hans.bosma@maastrichtuniversity.nl \\ * Correspondence: E-mail: majdisabahelzain@gmail.com, (MS)
}

\begin{abstract}
:
Vaccine uptake is one of the indicators that has been used to guide immunization programs. This study aimed to evaluate whether the measles vaccine uptake is predicted by measles vaccine hesitancy. A community-based cross-sectional study was conducted in urban districts in Khartoum state in February 2019. Measles vaccine uptake among children was measured as either fully vaccinated or partially/not vaccinated. The Parents Attitude about Childhood Vaccination (PACV) scale was used to measure measles vaccine hesitancy. Multivariate logistic regression was run to identify the predictors of measles vaccination uptake controlling for sociodemographic variables and the adjusted odds ratios (aORs) with $95 \% \mathrm{CI}$ were calculated. The receiver operator characteristic (ROC) curve was performed, besides area under the curve (AUC) for the PACV was computed. Data was collected from 495 participants. We found that measles vaccine hesitancy (PACV scores) predicted the uptake of measles vaccine after controlling other potential social confounders such as mother's age and the number of children (aOR 1.055, 95\% CI 1.028-1.028). Additionally, the ROC for the PACV yielded an area under the curve (AUC 0.686 (95\% CI 0.620-0.751, P <0.001). Our findings show that measles vaccine hesitancy in Sudan directly influences the uptake of the measles vaccine. Addressing the determinants of vaccine hesitancy through communication strategies will improve vaccine uptake.
\end{abstract}

Keywords: Measles vaccine; Vaccine hesitancy; Measles vaccine uptake; Immunization; Sudan; PACV

\section{Introduction}

Vaccine uptake is one of the indicators used to inform and guide immunization programs worldwide. It has been predicted by many factors that range from individual's level such as knowledge and attitude to the societal's levels including the health and immunization policies [1-3]. Findings from African countries showed that vaccine uptake was lower in rural than in urban locations. Factors related to a child's age, sex, birth order, and the number of children in the household were found to be significantly associated with vaccination. As well, parental factors such as; mothers' age, education, and socioeconomic status were found as predictors for vaccination [4-8]. 
Vaccine hesitancy is considered one of the most important predictors of vaccine uptake [9-12]. It has been named in 2019 by WHO as one of the top ten global health threats [13]. The Strategic Advisory Group of Experts on vaccine hesitancy (SAGE) has defined vaccine hesitancy as the "delay in acceptance or refusal of vaccines despite availability of vaccination services. Vaccine hesitancy is complex and context-specific, varying across time, place and vaccines". Vaccine hesitancy is influenced by some factors which are known as the 3Cs model which include complacency (perceived risks of vaccine-preventable diseases are low and no vaccines are needed), convenience (to access issues and constraints), and confidence (the level of trust in a vaccine or provider) $[9,10]$. Three tools were developed by the SAGE/WHO to measure vaccine hesitancy quantitatively and qualitatively and evaluated in many countries [10,11, 14-16]. One of these tools, the Vaccine Hesitancy Scale (VHS) was adapted and evaluated in Sudan which was reliable and has a moderately good convergent validity, however, it has a limitation in predicting the concurrent child's vaccination status. [17]

The impacts of vaccine hesitancy on vaccine uptake and demand are poorly understood in LMICs, suggesting a more complex relationship between supply-side and demand-side factors than in high-income countries [9-12, 16-21]. The Parent Attitudes about Childhood Vaccines survey (PACV) is a widely used tool that was designed to measure and identify vaccine-hesitant parents in different high and middle-income countries [2228]. Moreover, studies in the USA and Tennessee showed that the PACV could predict childhood immunization uptake. [29-32]

Globally, it is estimated that measles vaccination has averted about 23.2 million deaths between 2000 and 2018. As well, there has been a 66\% global decline in the annual incidence of measles with a $73 \%$ drop in measles-related death during the same period that is attributable to measles vaccination. Nevertheless, WHO has reported that measles cases rose by $300 \%$ in the first quarter of 2019, compared to the same period in 2018. [33, 34]

In Sudan, measles outbreaks hit different localities in the last two years, as there was an increase in the number of cases with $649 \%$ (4,978 confirmed cases in 2018) compared to the number of measles cases in 2017 [35]. The national vaccination coverage is suboptimal for the first and the second dose of the measles-containing vaccine $(88 \%$ and $72 \%$, respectively) [36]. The reasons behind the low uptake of the measles vaccine are not fully understood. Data from Sudan suggests the existence of measles vaccine hesitancy in Sudan with several social and behavioral drivers behind this hesitancy [17, 20,37]. In this study, we aimed to evaluate whether the measles vaccine uptake is predicted by measles vaccine hesitancy. This study will not only contribute to the acknowledged need for more research in LMIC about the impact of vaccine hesitancy on public health but also develop strategies to address the low uptake of measles vaccine at the local level.

\section{Materials and Methods}

\subsection{Study design}

The research design was a community-based cross-sectional study and was conducted in two urban districts in Omdurman locality in Khartoum state in February 2019. These two districts were selected for the study because they reflect the typical sociodemographic and socio-cultural situation in Sudan. As the two are in an urban setting, this may ensure a relative exposure to vaccination communication campaigns as well as accessibility to vaccination services. The latter is a prerequisite for the assessment of vaccine hesitancy.

\subsection{Population and sampling}

2.2.1. Population

The study population included parents/ guardians having at least one child aged 2 3 years old. Either mothers or fathers were eligible for participation. If there was more than one child in the same age range in the family, the parents/ guardians were asked to 
answer about only the youngest one to avoid recall bias. If both mother and father were available, they were asked to nominate one of themselves to complete the questionnaire.

\subsubsection{Sampling}

This study is part of a large research project about measles vaccine hesitancy in Sudan $[10,30]$. The sample size was calculated for the whole research using a power analysis for the association between measles vaccine hesitancy and the measles vaccination status (outcome), which showed that at least 386 participants were needed to yield an $80 \%$ power to detect an odds ratio of 1.7 at alpha level (5\%). We assumed the prevalence of the outcome, the measles vaccination status among the exposed group (hesitant parents) was $50 \%$ [38]. To cover for possible drop-out due to missing information on the important questions during the survey, we recruited more participants to complete a total of 500 participants (parents/caregivers) in the study.

We collected data from parents/caregivers in two different urban districts in Omdurman, Alsharafia (Wad Nubawi's administrative unit) and Abo Saaeed (Abo Saaeed's administrative unit). These two districts have similar characteristics in terms of urbanization, the same locality (i.e. Omdurman), exposure to vaccination and communication/information campaigns as well as relative availability of vaccine services as a prerequisite for assessment of vaccine hesitancy. However, people who live in these two districts have different socioeconomic backgrounds (i.e. education, employment, and income levels are higher in Abo Saaeed than in Alsharafia). Parents/ caregivers were selected in each district using consecutive sampling (convenience sample), as every parent/caregiver meeting the criteria of inclusion (had a child in the age range) was included in the study until the required sample size was achieved from each district.

\subsection{Data Collection}

Data were collected using a pre-tested, structured questionnaire. Data were collected by eight well-trained graduate female students from Ahfad University for Women.

\subsubsection{Measurements}

Dependent Variable

The dependent variable in this study was the measles vaccine uptake by the youngest child in the age range of 2-3 years (i.e. the measles vaccination status) which was measured as either fully vaccinated (i.e. two doses) or partially (i.e. single dose)/not vaccinated 0 . First, we asked the parents/ guardians to show the vaccination card of their youngest child (2-3 years). If there was no card, then we asked them to report about their child's measles vaccination status. Only $42.8 \%$ showed their children vaccination cards, however, $54.6 \%$ reported that they had cards but did not show them. We excluded from the analysis all parents/guardians who reported they did not know their children's vaccination status.

\section{Independent Variables}

In this study, we used the Parents Attitude about Childhood Vaccination (PACV) to measure measles vaccine hesitancy as the main independent variable. The PACV includes 15 items categorized in three domains; immunization behavior (items 1 and 2), perceived safety and efficacy (items 7-10), and general attitudes and trust (items 3-6 and 11-15). Items in this scale were scored using five points Likert scale ranging from strongly agree to strongly disagree. For measuring vaccine hesitancy, we combined the items for perceived safety and efficacy and the general attitude and trust items. These items were summed to a total score ranging from 0 to 30 . Parents with children who answered "don't know" in the behavior items of the scale (items 1 and 2) were considered missing data because this response likely reflected poor vaccination recall rather than immunization hesitancy, as suggested by other studies. The total raw hesitancy score was converted to a 0-100 scale. [22, 29]. The Cronbach's alpha was computed for this scale (Q3-Q15) which is 0.62 [17], [see Table A1].

Other independent variables, which were considered as potential confounders, were sociodemographic characteristics of the family including the family's income level (selfranking), mother's age, mother's education and employment, and the total number of children in the family, and the total number of the family's members. 


\subsection{Statistical Analysis}

Data analysis was performed using Statistical Package for Social Sciences (SPSS) (V 24). Frequencies were generated for the sociodemographic characteristics of the family. Frequencies of the PACV items were calculated. Chi-square test and Fisher's exact test (when the count in the cells is less than 5) were run to identify factors univariate associated with the dependent variable (i.e. measles vaccination status). Additionally, Pearson coefficients were calculated to assess the correlations between measles vaccine uptake and the socioeconomic factors, and measles vaccine hesitancy (PACV). A p-value of less than 0.05 was considered statistically significant. Only correlates and factors that were significantly related to uptake of measles vaccine were included in the multivariate analysis. Multiple logistic regression was used to identify the predictors of measles vaccination status controlling for sociodemographic variables and the adjusted odds ratios with $95 \%$ CI were calculated. The receiver operator characteristic (ROC) curve was performed, besides area under the curve (AUC) for the PACV was computed to evaluate the ability of the PACV for distinguishing and predicting the child's measles vaccination status.

Ethical consideration:

The study was approved by the Review Board (IRB) of the Ahfad University for Women (AUW) and the National Health Research Ethics Committee at the Federal Ministry of Health in Sudan (No.: 1-1-18).

\section{Results}

\subsection{Descriptive statistics and associations between the sociodemographic and paren- tal perceptions about the measles vaccine with the uptake of the measles vaccine.}

As shown by Table 1, 495 participants from Omdurman city were included: $30.7 \%$ from Wad Nubawi's district and 69.3\% from Abo Saeed district. The majority of the participants were mothers $(87.2 \%)$, with low participation of fathers (only $4.6 \%$ ). The mean age of the mothers who participated in the study was 31.14 ( $\mathrm{SD}=5.73$ ). About half of the participants $(50.1 \%)$ completed university followed by those who attended secondary schools (34.3\%). Nearly, three-quarters of the participants $(74.7 \%)$ were housewives. About $79.0 \%$ of the participants self-ranked their income level as a medium. The majority of the participants mentioned that they either have one or two children ( $44 \%$ and $45.9 \%$, respectively). As well, about a third of the participants reported that they have 3-4 members in their households.

Moreover, we found that measles vaccine uptake was highly associated with the mother's employment, as self-employed mothers were more likely to only partially or not vaccinate their children followed by mothers who were workers and housewives ( $p$-value $<0.017$ ). The number of children was associated with measles vaccine uptake, as families with three or more children were more likely to only partially or not vaccinate their children with measles vaccine compared to mothers with one child ( $p$-value $=0.041$ ), see (Table 1). Families with 5 or more members have a lower tendency to fully vaccinate their children than families with less than 3-4 members. 
Table 1. Association of the characteristics of the surveyed parents/guardians with measles vaccination status. $\mathrm{N}=495$

\section{Measles vaccination uptake/status}

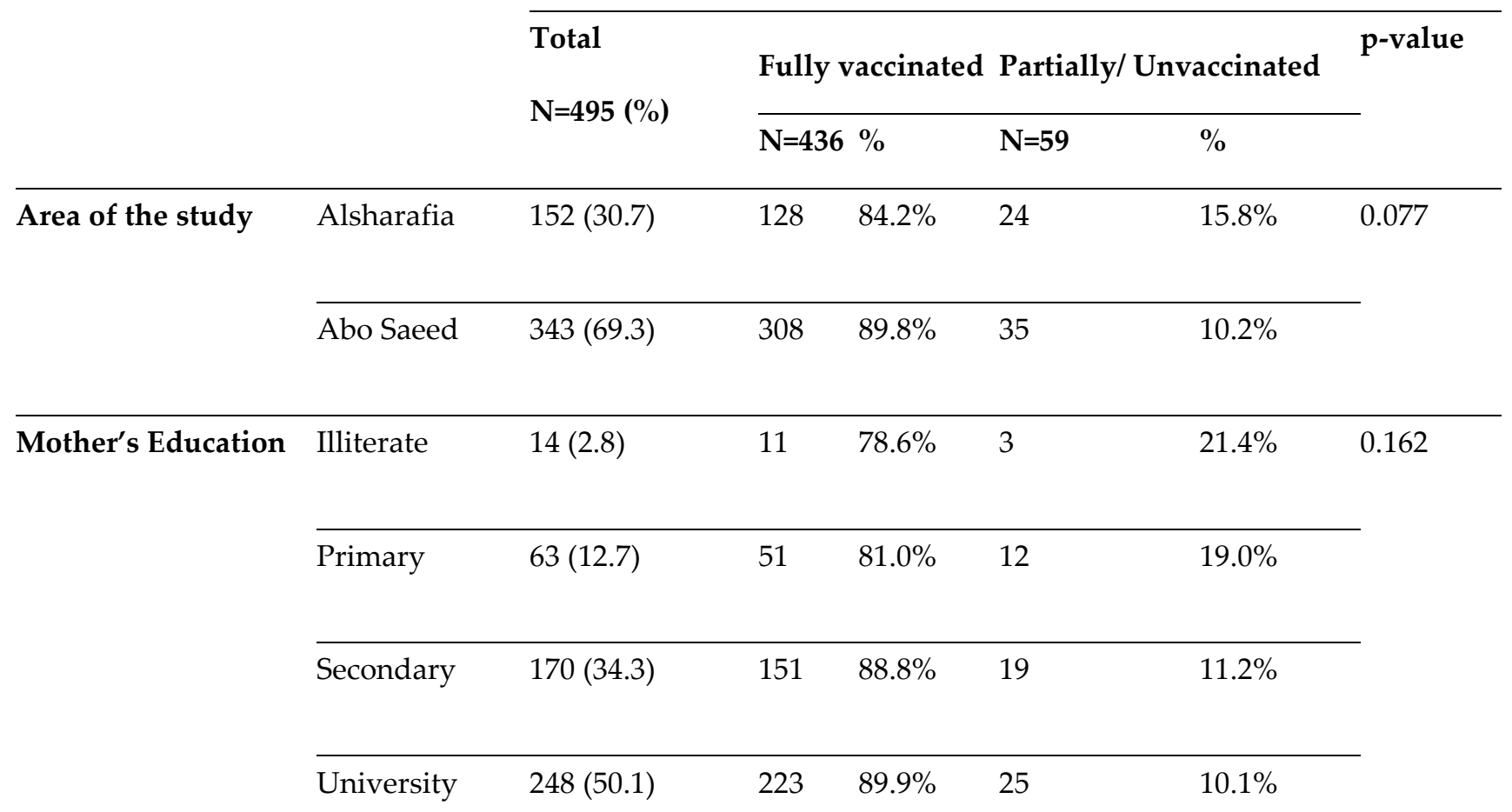

\begin{tabular}{|c|c|c|c|c|c|c|c|}
\hline \multirow{7}{*}{$\begin{array}{l}\text { Mother's Employ- } \\
\text { ment }\end{array}$} & Housewife & $370(74.7)$ & 323 & $87.3 \%$ & 47 & $12.7 \%$ & \multirow[t]{2}{*}{$0.017^{* b}$} \\
\hline & Student & $11(2.2)$ & 10 & $90.9 \%$ & 1 & $9.1 \%$ & \\
\hline & Worker & $14(2.8)$ & 12 & $85.7 \%$ & 2 & $14.3 \%$ & \\
\hline & Officer & $50(10.1)$ & 48 & $96.0 \%$ & 2 & $4.0 \%$ & \\
\hline & $\begin{array}{l}\text { Professional } \\
\text { (e.g. Engineer) }\end{array}$ & $33(6.7)$ & 32 & $97.0 \%$ & 1 & $3.0 \%$ & \\
\hline & Self-employed & $16(3.2)$ & 10 & $62.5 \%$ & 6 & $37.5 \%$ & \\
\hline & Others & $1(0.2)$ & 1 & $100.0 \%$ & 0 & $0.0 \%$ & \\
\hline \multirow{2}{*}{$\begin{array}{l}\text { Income Level } \\
\text { (Self-Ranking) }\end{array}$} & High & $70(14.1)$ & 65 & $92.9 \%$ & 5 & $7.1 \%$ & \multirow[t]{2}{*}{0.268} \\
\hline & Medium & $391(79.0)$ & 343 & $87.7 \%$ & 48 & $12.3 \%$ & \\
\hline
\end{tabular}




\begin{tabular}{|c|c|c|c|c|c|c|c|}
\hline & Low & $34(6.9)$ & 28 & $82.4 \%$ & 6 & $17.6 \%$ & \\
\hline \multirow[t]{3}{*}{ Number of Children } & 1 & $218(44.0)$ & 185 & $84.9 \%$ & 33 & $15.1 \%$ & $0.041^{*}$ \\
\hline & 2 & 227 (45.9) & 209 & $92.1 \%$ & 18 & $7.9 \%$ & \\
\hline & 3 and more & $50(10.1)$ & 42 & $84.0 \%$ & 8 & $16.0 \%$ & \\
\hline \multirow{3}{*}{$\begin{array}{l}\text { Total number of } \\
\text { household's mem- } \\
\text { bers }\end{array}$} & $3-4$ & $178(36.0)$ & 169 & $94.9 \%$ & 9 & $5.1 \%$ & $0.002^{*}$ \\
\hline & $5-6$ & $159(32.1)$ & 134 & $84.3 \%$ & 25 & $15.7 \%$ & \\
\hline & 7 and more & $158(31.9)$ & 133 & $84.2 \%$ & 25 & $15.8 \%$ & \\
\hline
\end{tabular}

3.2. Pearson correlations between measles vaccine uptake and the socioeconomic factors, and measles vaccine hesitancy (PACV)

Pearson correlation was run to assess; firstly, the relation between the uptake of measles vaccine and the socioeconomic factors, and measles vaccine hesitancy (PACV); and secondly to assess multicollinearity between the correlates to avoid its negative effect on the multivariate analysis. Table 2 shows that uptake of measles vaccine among children is strongly correlated with the PACV scores and number of household's members (0.22 and 0.14; p-value <0.001), weak correlation with mother's employment $(0.091 ; \mathrm{p}$-value<0.05), and negative correlation with mother's education (-0.091; $\mathrm{p}$-value<0.05).

Table 2: Pearson correlations between measles vaccine uptake and the socioeconomic factors, and measles vaccine hesitancy (PACV)

\begin{tabular}{|c|c|c|c|c|c|c|c|c|c|}
\hline & $\begin{array}{l}\text { Area of } \\
\text { the } \\
\text { Study }\end{array}$ & $\begin{array}{l}\text { Mothers' } \\
\text { Age }\end{array}$ & $\begin{array}{l}\text { Mothers' } \\
\text { Education }\end{array}$ & $\begin{array}{l}\text { Mother's } \\
\text { Employment }\end{array}$ & $\begin{array}{l}\text { Family } \\
\text { Income } \\
\text { Level }\end{array}$ & $\begin{array}{l}\text { Number } \\
\text { of Chil- } \\
\text { dren }\end{array}$ & $\begin{array}{l}\text { Number of } \\
\text { House- } \\
\text { hold's mem- } \\
\text { bers }\end{array}$ & $\begin{array}{l}\text { PACV } \\
\text { scores }\end{array}$ & $\begin{array}{l}\text { Measles } \\
\text { Vaccine } \\
\text { Uptake }\end{array}$ \\
\hline Area of the Study & $X$ & & & & & & & & \\
\hline Mothers' Age & $0.116^{*}$ & $X$ & & & & & & & \\
\hline Mothers' Education & $0.160^{* *}$ & 0.006 & $X$ & & & & & & \\
\hline $\begin{array}{l}\text { Mother's Employ- } \\
\text { ment }\end{array}$ & 0.034 & 0.045 & $0.191^{* *}$ & $x$ & & & & & \\
\hline $\begin{array}{l}\text { Family Income } \\
\text { Level }\end{array}$ & $-0.175^{* *}$ & 0.005 & $-0.293^{* *}$ & $-0.183^{* *}$ & $x$ & & & & \\
\hline
\end{tabular}




\begin{tabular}{l|c|c|c|c|c|c|c|c|c}
\hline $\begin{array}{l}\text { Number of Chil- } \\
\text { dren }\end{array}$ & -0.017 & -0.013 & -0.053 & -0.038 & 0.067 & $X$ & & & \\
\hline $\begin{array}{l}\text { Number of House- } \\
\text { hold's members }\end{array}$ & 0.047 & $0.402^{* *}$ & $-0.266^{* *}$ & -0.067 & $0.144^{* *}$ & $0.219^{* *}$ & $X$ & & \\
\hline PACV scores & -0.039 & 0.037 & -0.011 & 0.031 & 0.009 & $0.103^{*}$ & 0.082 & $X$ & \\
\hline $\begin{array}{l}\text { Measles Vaccine } \\
\text { Uptake }\end{array}$ & -0.080 & $0.091^{*}$ & $-0.091^{*}$ & -0.014 & 0.073 & -0.048 & $0.139^{* *}$ & $0.222^{* *}$ & $X$ \\
\hline
\end{tabular}

*Significant at the 0.05 level (2-tailed), **Significant at the 0.01 level (2-tailed), N=495

\subsection{Multiple logistic regression analysis}

To assess whether the measles vaccine hesitancy (PACV scores) predicts the uptake of the measles vaccine, we ran a multivariable logistic regression model with adjusting all sociodemographic variables that were significantly associated with the uptake of the measles vaccine at the bivariate level. The logistic regression analysis results are presented in Table 3 . We found that measles vaccine hesitancy (PACV scores) predicted the uptake of measles vaccine $\mathrm{OR}=1.054$ (95\% C.I, 1.028-1.081).

Table 3. Predictors of partial vaccination or not vaccination with measles vaccine in Khartoum state, Sudan

\begin{tabular}{lcc}
\hline Predictors & OR (95\% C.I of OR) & aOR (95\% C.I of OR) \\
\hline PACV scores & $1.053^{*}(1.030-1.078)$ & $1.054^{*}(1.028-1.081)$ \\
\hline Age of mother & $1.049^{*}(1.001-1.100)$ & $1.020(0.966-1.076)$ \\
\hline Number of household's members** & & \\
\hline 3-4 (ref) & & \\
\hline 5-6 & $3.503^{*}(1.582-7.757)$ & $3.317^{*}(1.450-7.589)$ \\
\hline 7 and more & $3.530^{*}(1.594-7.817)$ & $2.528^{*}(1.044-7.881)$ \\
\hline Mother's employment & & \\
\hline Housewife (ref) & $0.687(0.086-5.491)$ & $0.575(0.065-5.064)$ \\
\hline Student & $1.145(0.249-5.279)$ & $0.922(0.185-4.586)$ \\
\hline$\quad$ Worker & $.286(0.067-1.217) 0$ & $0.317(0.073-1.377)$ \\
\hline Officer & $.215(0.029-1.609) 0$ & $0.231(0.030-1.770)$ \\
\hline Professional (e.g. Engineer, Doctor) & $4.123^{*}(1.432-11.870)$ & $3.189(0.868-11.718)$ \\
\hline Self-employed &
\end{tabular}

${ }^{*} \mathrm{p}<0.05, \mathrm{aOR}=$ Adjusted odds ratio; ref=Reference category; ${ }^{* *}$ Number of household members we strongly related to the mother's education and number of children (Pearson coefficient $=-0.266$ and $0.219 ; \mathrm{p}<0.001$ ), therefore, only the number of household members was included in the multivariate analysis.

\subsection{ROC curve}

The PACV's scores were analyzed using ROC analysis to describe their ability to predict the child's measles vaccination uptake. The nonparametric analysis of the ROC for the PACV yielded an area under the curve (AUC) of 0.686 (95\% CI=0.620, 0.751) (P 
$<0.001$; Figure 2). This reveals that the test can significantly predict the measles vaccine uptake among children.

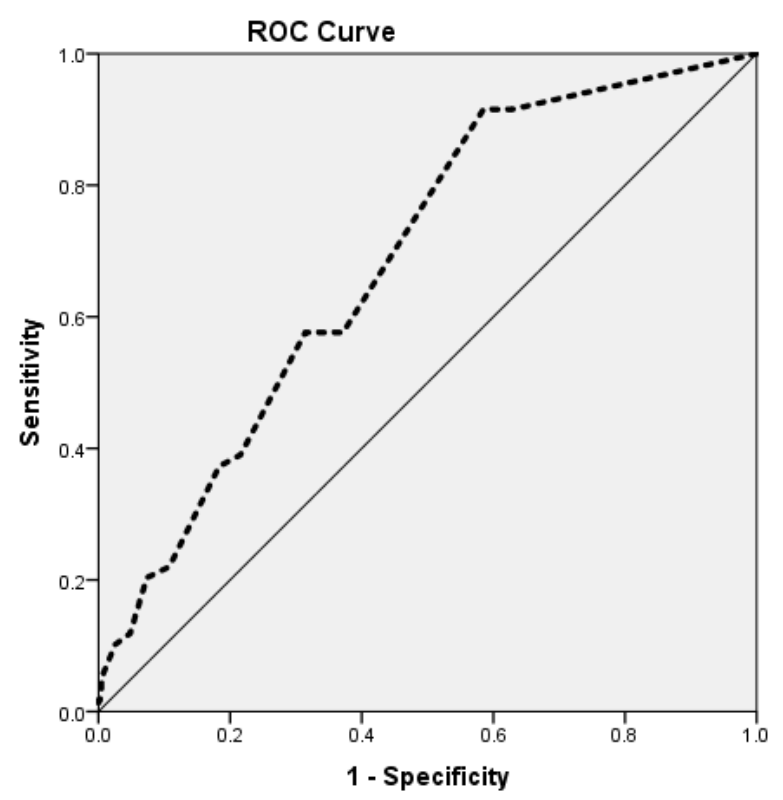

Figure 1. Receiver Operating Characteristic (ROC) analysis of the PACV's scores for screening of vaccine hesitancy.

\section{Discussion}

The present study aimed to assess whether the measles vaccine uptake can be predicted by measles vaccine hesitancy (PACV scores) in two urban areas in Khartoum state.

Our study's findings showed that about $12 \%$ of the children (2-3 years) were either under-immunized with only a single dose of measles vaccine or were unimmunized at all. This finding mirrors results from the annual statistical report in 2019, as the rate of receiving the first dose of measles vaccine in Khartoum state and at the national level, was estimated at $88 \%[36,40]$. Our data was collected only from urban areas, which represent about $30 \%$ of Sudan [41]. We purposively targeted urban areas to ensure the relative availability of vaccines services and thus control other factors related to vaccine access issues. People in rural areas in Sudan are underserviced with vaccines services, which reflect geographical and socioeconomic inequality. Although measles vaccine coverages in both urban and rural areas are suboptimal at the national level, children in urban areas who received the second dose of measles vaccine are $8 \%$ higher than children in rural areas ( $85.4 \%$ and $77.5 \%$, respectively). [41]

Official reports in Sudan indicate that measles is the third cause of death among children under five and the first among vaccine-preventable diseases. [39, 40]. WHO recommended countries that aim to eliminate measles should achieve $\geq 95 \%$ coverage with both doses (i.e. the first and the second one) to all children in each district [42]. Studies from different African countries including Sudan suggested that countries with vaccine access issues are far away from achieving the measles elimination goal.[4-8, 20]

Moreover, one major access-related issue might be the presentation of the measles vaccine in multiple doses (10 doses per vial). This results in conducting 1-2 sessions per week in many low-income countries to comply with the open vial policy, which recommends discarding the ten-dose vial after six hours from opening the vial if unused as well as to reduce the vaccine wastage. Furthermore, these access issues may affect negatively vaccine acceptance, as parents are actively trying to get their child vaccinated with the measles vaccine, but turn away when the provider refuses to open the measles vaccine vial $[4-8,19,20]$. Analysis for immunization policy as well as cost-effective analysis is needed to anticipate what will happen if the ten-dose vial of measles vaccine (i.e. open 
vial policy) is shifted to a five-dose vial in Sudan as it succeeded in many LMICs countries [43-46].

Importantly, our study underscored that measles vaccine hesitancy among parents influences the uptake of measles vaccine among children (aOR 1.054, 95\% CI 1.028-1.081). Additionally, the nonparametric analysis of the ROC for the PACV yielded an area under the curve (AUC 0.686 (95\% CI 0.620-0.751) (P<0.001). Both findings reveal that the PACV can significantly predict the measles vaccine uptake among children. As the present study was conducted in a low-income context, it supports the predictive validity of the PACV in determining the vaccination status of children as shown in previous studies in high and middle-income countries. [33, 37-40]

Interestingly, although mothers' education and the income level of the family were not significantly associated with the uptake of the measles vaccine, however, our findings showed that mothers who are not educated, their children are twice as much only partially or unvaccinated than mothers who attained university education $(21.4 \%$ and $10.1 \%$, respectively). As well, the proportion of partially/unvaccinated is more than twice in families who reported a low-income level compared to those who reported a high-income level (17.6\% and $7.1 \%$, respectively). These findings may underscore socio-economic inequalities related to the uptake of the measles vaccine. In terms of intervention strategies, these lower socio-economic groups should be prioritized as, early target groups.

\section{Limitation}

We acknowledge some limitations related to our study, therefore, the study's findings should be interpreted within the context of this study. These include that our study was conducted in two urban districts in Omdurman locality in Khartoum state, which may have led to a household selection of relatively higher educated families, as about half of the female participants $(50.1 \%)$ had attained university education. This rate is higher than the average rates for the females who are attending university (about 15\% and 30\% at the national and Khartoum state levels, respectively) [47]. These districts have also a higher rate of vaccination, which can be explained also by the level of education though it was not statistically significant, as well as the relative availability and accessibility of vaccination services. Remote and rural areas of Sudan were not included in this study. In these areas vaccination services for households are less easily available and accessible. From a gender perspective, we missed fathers' perception and perspective in this study, as data were collected from 10:00 am- to 5:00 pm during working hours of most fathers. However, Sudanese mothers are mostly the ones that are the first persons responsible for the health and prevention of sickness of their children/family and should know the health situation best; therefore, some parents preferred her participation in the study to the father's participation.

\section{Conclusions}

Our study findings underscored that measles vaccine hesitancy influences the uptake of measles vaccine and that the PACV is predicting the immunization status of Sudanese children. In light of these findings, we suggest that intervening on measles vaccine hesitancy will have a direct impact on the uptake of the measles vaccine in Sudan. Improving the vaccination status of Sudanese children could be achieved through developing and implementing immunization communication strategies that address the determinants of vaccine hesitancy that should increase the confidence in the measles vaccine by correcting misinformation, debunking myths and rumors about vaccines, and scientifically addressing the vaccine safety issues. Intervention strategies should prioritize parents in lower socio-economic groups as they showed lower uptake of measles vaccine.

Author Contributions: Conceptualization, M.S, H.B, and B.B.; methodology, M.S, and M.M.; validation, H.B., and B.B.; formal analysis, M.S.; investigation, M.S.; resources, M.S. and H.B; data curation, H.B, and B.B.; writing - original draft preparation, M.S.; writing - review and editing, M.M., H.B, and B.B.; visualization, M.S.; supervision, M.M., H.B and B.B.; project administration, M.S.; funding acquisition, B.B. All authors have read and agreed to the published version of the manuscript. 
Funding: This research received no external funding.

\section{Institutional Review Board Statement:}

The study was approved by the Review Board (IRB) of the Ahfad University for Women (AUW) and the National Health Research Ethics Committee at the Federal Ministry of Health in Sudan .

Informed Consent Statement: Informed consent was obtained from all subjects involved in the study.

\section{Data Availability Statement:}

Acknowledgments: We are grateful to the students from Ahfad University for Women (AUW) in Sudan, who helped collect the data. A special thanks to Dr. Douglas J. Opel from the School of Medicine at the University of Washington for providing us with the PACV analysis' guide.

Conflicts of Interest: The authors declare no conflicts of interest.

\section{Appendix A}

Table A1: Frequency distribution of the 15 PACV items $(\mathrm{N}=495)$.

\section{References}

1. Kumar S, Quinn SC, Kim KH, Musa D, Hilyard KM, Freimuth VS. The social-ecological model as a framework for determinants of 2009 H1N1 influenza vaccine uptake in the United States. Health Educ Behav. 2012 Apr;39(2):229-43. doi: 10.1177/1090198111415105. Epub 2011 Oct 7. PMID: 21984692; PMCID: PMC3916095.

2. Kolff CA, Scott VP, Stockwell MS. The use of technology to promote vaccination: A social ecological model based framework. Human vaccines \& immunotherapeutics. 2018 Jul 3;14(7):1636-46.

3. Olaniyan A, Isiguzo C, Hawk M. The Socioecological Model as a framework for exploring factors influencing childhood immunization uptake in Lagos state, Nigeria. BMC Public Health. 2021 Dec;21(1):1-0.

4. Wiysonge CS, Uthman OA, Ndumbe PM, Hussey GD. Individual and contextual factors associated with low childhood immunisation coverage in sub-Saharan Africa: a multilevel analysis. PLoS One. 2012;7(5):e37905. doi:10.1371/journal.pone.0037905

5. Mazige FM, Kalwani JD, Kakoko DC. Social determinants of immunization services uptake in developing countries: a systematic review. Pan African Medical Journal. 2016 Jul 7;24(197).

6. Magodi R, Mmbaga EJ, Massaga J, Lyimo D, Mphuru A, Abade A. Factors associated with non-uptake of measles-rubella vaccine second dose among children under five years in Mtwara district council, Tanzania, 2017. Pan Afr Med J. 2019 May 29;33:67. doi: 10.11604/pamj.2019.33.67.17055.

7. Bangura JB, Xiao S, Qiu D, Ouyang F, Chen L. Barriers to childhood immunization in sub-Saharan Africa: a systematic review. BMC Public Health. 2020 Dec;20(1):1-5.

8. Adetokunboh O, Iwu-Jaja CJ, Nnaji CA, Ndwandwe D. Missed opportunities for vaccination in Africa. Curr Opin Immunol. 2021 Aug;71:55-61. doi: 10.1016/j.coi.2021.05.002. Epub 2021 Jun 1. PMID: 34087523.

9. MacDonald NE. Vaccine hesitancy: definition, scope and determinants. Vaccine 2015; 33: 4161-64.

10. World Health Organization. Report of the SAGE working group on vaccine hesitancy. Geneva, Switzerland: WHO. 2014 Nov.

11. Larson HJ, Jarrett C, Schulz WS, Chaudhuri M, Zhou Y, Dube E, et al. Measuring vaccine hesitancy: The development of a survey tool. Vaccine. 2015 Aug 14;33(34):4165-75. Epub 2015 Apr 18. pmid:25896384.

12. Sara Cooper, Cornelia Betsch, Evanson Z. Sambala, Nosicelo Mchiza\& Charles S. Wiysonge (2018) Vaccine hesitancy - a potential threat to the achievements of vaccination programs in Africa, Human Vaccines \& Immunotherapeutics, 14:10, 2355-2357, DOI: $10.1080 / 21645515.2018 .1460987$

13. World Health Organization: Ten threats to global health in 2019. Available from: https://www.who.int/emergencies/ten-threatsto-global-health-in-2019 (Last accessed 25/01/2021).

14. Shapiro GK, Tatar O, Dube E, Amsel R, Knauper B, Naz A, et al. The vaccine hesitancy scale: Psychometric properties and validation. Vaccine. 2018 Jan 29;36(5):660-667. Epub 2017 Dec 27. pmid:29289384.

15. 21.Luyten J, Bruyneel L, van Hoek AJ. Assessing vaccine hesitancy in the UK population using a generalized vaccine hesitancy survey instrument. Vaccine. 2019 Apr 24;37(18):2494-2501. Epub 2019 Mar 30. pmid:30940484

16. Domek GJ, O'Leary ST, Bull S, Bronsert M, Contreras-Roldan IL, Bolaños Ventura GA, Kempe A, Asturias EJ. Measuring vaccine hesitancy: Field testing the WHO SAGE Working Group on Vaccine Hesitancy survey tool in Guatemala. Vaccine. 2018 Aug 23;36(35):5273-5281. doi: 10.1016/j.vaccine.2018.07.046. Epub 2018 Jul 27. PubMed PMID: 30061026; PubMed Central PMCID: PMC6145454.

17. Sabahelzain MM, Dubé E, Moukhyer M, Larson HJ, van den Borne B, Bosma H. Psychometric properties of the adapted measles vaccine hesitancy scale in Sudan. PloS one. 2020 Aug 6;15(8):e0237171.

18. Cooper S, Okeibunor JC, Wiyeh A, Wiysonge CS. Knowledge advances and gaps on the demand side of vaccination. The Lancet Infectious Diseases. 2019 Jan 1;19(1):13-5.

19. Bedford H, Attwell K, Danchin M, Marshall H, Corben P, Leask J. Vaccine hesitancy, refusal and access barriers: The need for clarity in terminology. Vaccine. 2018 Oct 22;36(44):6556-6558. doi: 10.1016/j.vaccine.2017.08.004. Epub 2017 Aug 19. PMID: 28830694 . 
20. Sabahelzain MM, Moukhyer M, Dubé E, Hardan A, van den Borne B, Bosma H. Towards a further understanding of measles vaccine hesitancy in Khartoum state, Sudan: A qualitative study. PloS one. 2019 Jun 20;14(6):e0213882. pmid:31220092.

21. Wallace AS, Wannemuehler K, Bonsu G, Wardle M, Nyaku M, Amponsah-Achiano K, Dadzie JF, Sarpong FO, Orenstein WA, Rosenberg ES, Omer SB. Development of a valid and reliable scale to assess parents' beliefs and attitudes about childhood vaccines and their association with vaccination uptake and delay in Ghana. Vaccine. 2019 Feb 4;37(6):848-856. doi: 10.1016/j.vaccine.2018.12.055. Epub 2019 Jan 11. PMID: 30642731; PMCID: PMC6534746.

22. Opel DJ, Taylor JA, Mangione-Smith R, Solomon C, Zhao C, Catz S, Martin D. Validity and reliability of a survey to identify vaccine-hesitant parents. Vaccine. 2011 Sep 2;29(38):6598-605. doi: 10.1016/j.vaccine.2011.06.115. Epub 2011 Jul 16. PMID: 21763384.

23. Bonsu NEM, Mire SS, Sahni LC, Berry LN, Dowell LR, Minard CG, Cunningham RM, Boom JA, Voigt RG, Goin-Kochel RP. Understanding Vaccine Hesitancy Among Parents of Children With Autism Spectrum Disorder and Parents of Children With Non-Autism Developmental Delays. J Child Neurol. 2021 Sep;36(10):911-918. doi: 10.1177/08830738211000505. Epub 2021 May 28. PMID: 34048284; PMCID: PMC8440329.

24. Olarewaju VO, Jafflin K, Deml MJ, Zimmermann C, Sonderegger J, Preda T, Staub H, Kwiatkowski M, Kloetzer A, Huber BM, Merten S, Tarr PE. Application of the Parent Attitudes about Childhood Vaccines (PACV) survey in three national languages in Switzerland: Exploratory factor analysis and Mokken scale analysis. Hum Vaccin Immunother. 2021 Aug 3;17(8):2652-2660. doi: 10.1080/21645515.2021.1894894. Epub 2021 Mar 24. PMID: 33760690; PMCID: PMC8475569.

25. Wagner AL, Huang Z, Ren J, Laffoon M, Ji M, Pinckney LC, Sun X, Prosser LA, Boulton ML, Zikmund-Fisher BJ. Vaccine Hesitancy and Concerns About Vaccine Safety and Effectiveness in Shanghai, China. Am J Prev Med. 2021 Jan;60(1 Suppl 1):S77S86. doi: 10.1016/j.amepre.2020.09.003. Epub 2020 Nov 12. PMID: 33189502; PMCID: PMC7877188.

26. Whelan SO, Moriarty F, Lawlor L, Gorman KM, Beamish J. Vaccine hesitancy and reported non-vaccination in an Irish pediatric outpatient population. Eur J Pediatr. 2021 Sep;180(9):2839-2847. doi: 10.1007/s00431-021-04039-6. Epub 2021 Mar 27. PMID: 33774718.

27. Della Polla G, Pelullo CP, Napolitano F, Angelillo IF. HPV vaccine hesitancy among parents in Italy: a cross-sectional study. Hum Vaccin Immunother. 2020 Nov 1;16(11):2744-2751. doi: 10.1080/21645515.2020.1744367. Epub 2020 Apr 16. PMID: 32298210; PMCID: PMC7734096.

28. Abd Halim H, Abdul-Razak S, Md Yasin M, Isa MR. Validation study of the Parent Attitudes About Childhood Vaccines (PACV) questionnaire: the Malay version. Hum Vaccin Immunother. 2020 May 3;16(5):1040-1049. doi: 10.1080/21645515.2019.1674112. Epub 2019 Oct 29. PMID: 31567057; PMCID: PMC7227665.

29. Opel DJ, Taylor JA, Zhou C, Catz S, Myaing M, Mangione-Smith R. The relationship between parent attitudes about childhood vaccines survey scores and future child immunization status: a validation study. JAMA pediatrics. 2013 Nov 1;167(11):1065-71

30. Williams SE, Morgan A, Opel D, Edwards K, Weinberg S, Rothman R. Screening tool predicts future underimmunization among a pediatric practice in Tennessee. Clinical pediatrics. $2016 \mathrm{Jun} ; 55(6): 537-42$.

31. Glanz JM, Wagner NM, Narwaney KJ, Kraus CR, Shoup JA, Xu S, O'Leary ST, Omer SB, Gleason KS, Daley MF. Web-based social media intervention to increase vaccine acceptance: a randomized controlled trial. Pediatrics. 2017 Dec 1;140(6).

32. Williams SE, Rothman RL, Offit PA, Schaffner W, Sullivan M, Edwards KM. A randomized trial to increase acceptance of childhood vaccines by vaccine-hesitant parents: a pilot study. Academic pediatrics. 2013 Sep 1;13(5):475-80.

33. Patel MK, Dumolard L, Nedelec Y, Sodha SV, Steulet C, Gacic-Dobo M, Kretsinger K, McFarland J, Rota PA, Goodson JL. Progress Toward Regional Measles Elimination-Worldwide, 2000-2018. Morbidity and Mortality Weekly Report. 2019 Dec 6;68(48):1105.

34. Gramigna J. 4 European countries lose measles-free status; US on the brink. Infectious Diseases in Children. 2019 Sep 1;32(9):7-

35. Gallup. Wellcome Global Monitor - First Wave Findings. 2019 June 19. Available from: https://wellcome.ac.uk/sites/default/files/wellcome-global-monitor-2018.pdf

36. Sudan: WHO and UNICEF estimate of immunization coverage: 2018 revision. Available from: www.sho.gov.sd

37. Attwell K, Betsch C, Dube E, Gagneur A, Omer S, Picot V, Sivelä J, Suggs LS, Thomson A. 7th Vaccine Acceptance Meeting. Sep 2019, Annecy, France.

38. Fleiss, J.L. Statistical Methods for Rates and Proportions.2nd Ed. Newyork: John Wiley, 1981. Print.

39. Ministry of Health in Sudan: Annual Statistical Report 2018. Available from: www.sho.gov.sd

40. Ministry of Health in Sudan: Annual Statistical Report 2019. Available from: www.sho.gov.sd

41. Central Bureau of Statistics (CBS), UNICEF Sudan. Multiple Indicator Cluster Survey 2014 Sudan. Final Report. Khartoum, Sudan: CBS and UNICEF; 2016

42. World Health Organization. Measles vaccines: WHO position paper. Weekly Epidemiological Record= Relevé épidémiologique hebdomadaire. 2009;84(35):349-60.

43. Heaton A, Krudwig K, Lorenson T, Burgess C, Cunningham A, Steinglass R. Doses per vaccine vial container: An understated and underestimated driver of performance that needs more evidence. Vaccine. 2017 Apr 19;35(17):2272-2278. doi: 10.1016/j.vaccine.2016.11.066. Epub 2017 Feb 3. PMID: 28162822.

44. Krudwig K, Knittel B, Karim A, Kanagat N, Prosser W, Phiri G, Mwansa F, Steinglass R. The effects of switching from 10 to 5 dose vials of MR vaccine on vaccination coverage and wastage: A mixed-method study in Zambia. Vaccine. 2020 Aug 18;38(37):5905-5913. doi: 10.1016/j.vaccine.2020.07.012. Epub 2020 Jul 21. PMID: 32703746; PMCID: PMC7427328.

45. Kanagat N, Krudwig K, Wilkins KA, Kaweme S, Phiri G, Mwansa FD, Mvundura M, Robertson J, Kristensen D, Gueye A, Dao SD, Thai PQ, Nguyen HT, Tran TC. Health Care Worker Preferences and Perspectives on Doses per Container for 2 Lyophilized 
Vaccines in Senegal, Vietnam, and Zambia. Glob Health Sci Pract. 2020 Dec 23;8(4):680-688. doi: 10.9745/GHSP-D-20-00112. PMID: 33361235; PMCID: PMC7784065.

46. Kanagat N, Krudwig K, Wilkins KA, Kaweme S, Phiri G, Mwansa FD, Mvundura M, Robertson J, Kristensen D, Gueye A, Dao SD, Thai PQ, Nguyen HT, Tran TC. Health Care Worker Preferences and Perspectives on Doses per Container for 2 Lyophilized Vaccines in Senegal, Vietnam, and Zambia. Glob Health Sci Pract. 2020 Dec 23;8(4):680-688. doi: 10.9745/GHSP-D-20-00112. PMID: 33361235; PMCID: PMC7784065.

47. UNESCO. World Inequality Database on Education (WIDE). Available online: https://www.education-inequalities.org (accessed on 10 October 2021) 